\title{
Degradation of dichloroaniline isomers by a newly isolated strain, Bacillus megaterium IMT21
}

\author{
Xie-Feng Yao, ${ }^{1,2}$ † Fazlurrahman Khan, ${ }^{3}$ † Rinku Pandey, ${ }^{2}$ \\ Janmejay Pandey, ${ }^{2,4}$ Roslyn G. Mourant, ${ }^{2}$ Rakesh K. Jain, ${ }^{3}$ Jian-Hua Guo, ${ }^{1}$ \\ Robyn J. Russell, ${ }^{2}$ John G. Oakeshott ${ }^{2}$ and Gunjan Pandey ${ }^{2}$ \\ ${ }^{1}$ Department of Plant Pathology, College of Plant Protection, Nanjing Agricultural University, Key \\ Laboratory of Monitoring and Management of Crop Diseases and Pest Insects, Ministry of \\ Agriculture, Nanjing 210095, China \\ ${ }^{2}$ CSIRO Ecosystem Sciences, GPO Box 1700, Canberra, ACT 2601, Australia \\ ${ }^{3}$ Institute of Microbial Technology, Sector-39A, Chandigarh 160036, India \\ ${ }^{4}$ Institute of Biophysical Dynamics, Gordon Center for Integrative Sciences, University of Chicago, IL \\ 60637, USA
}

Correspondence

Gunjan Pandey

Gunjan.Pandey@csiro.au

Received 12 September 2010

Revised 8 December 2010

Accepted 9 December 2010

\begin{abstract}
An efficient 3,4-dichloroaniline (3,4-DCA)-mineralizing bacterium has been isolated from enrichment cultures originating from a soil sample with a history of repeated exposure to diuron, a major metabolite of which is 3,4-DCA. This bacterium, Bacillus megaterium IMT21, also mineralized 2,3-, 2,4-, 2,5- and 3,5-DCA as sole sources of carbon and energy. These five DCA isomers were degraded via two different routes. 2,3-, 2,4- and 2,5-DCA were degraded via previously unknown dichloroaminophenol metabolites, whereas 3,4- and 3,5-DCA were degraded via dichloroacetanilide.
\end{abstract}

\section{INTRODUCTION}

Dichloroanilines (DCAs) are widely used intermediates in commercial syntheses of various azo dyes, herbicides, paints, cosmetics and other industrial chemicals. However, their stability and toxicity also render them hazardous when released into the environment (NTP Comparative Toxicity Studies, 1998; Argese et al., 2001; Lo et al., 1990; Padmanabhan et al., 2006). 3,4- and 3,5-DCA are particularly noxious, although 2,3-, 2,4- and 2,5-DCA are also highly toxic (Claver et al., 2006; Götz et al., 1998; Peng et al., 2005; Valentovic et al., 1995). 3,4-DCA is the most commonly used DCA isomer in the chemical industry (Giacomazzi \& Cochet, 2004; Valentovic et al., 1995) and it is also the major breakdown product of the widespread phenylamide herbicides diuron, linuron and propanil. In fact it is detected more frequently in environmental samples than the parent herbicides (Claver et al., 2006; Giacomazzi \& Cochet, 2004).

Several bacterial strains have been isolated that can degrade 3,4-DCA, and at least one of these has also been reported to degrade 2,3- 2,4- and 2,5-DCA (Table 1). A complete degradation pathway has not been elucidated for 3,4-DCA,

†These authors contributed equally to this work.

Abbreviation: DCA, dichloroaniline.

The GenBank accession number for the 16S rRNA gene sequence reported in this paper is GU479395. but 4-chloroaniline, 3-chloro-4-hydroxyaniline, 4-chloro3-hydroxyaniline, 4,5-dichlorocatechol and 1,2-dichlorobenzene have been suggested as intermediates, ultimately leading to mineralization via different catabolic routes (Table 1). Furthermore, 3,4-dichloroacetanilide, 3,3',4, $4^{\prime}$-tetrachloroazobenzene and 3,4-dichloro- $\mathrm{N}$-(3,4-dichlorophenyl)benzamide have also been reported as transformation products or minor intermediates, suggesting that different degradation pathways could be operating in some of these strains (Table 1).

In this communication we report the isolation of a new bacterial strain, Bacillus megaterium IMT21, which is able to mineralize five DCA isomers, 2,3-, 2,4-, 2,5-, 3,4- and 3,5-DCA, as sole sources of carbon and energy. We find that the catabolic pathway used depends on the isomer. 3,4- and 3,5-DCA are degraded via dichloroacetanilide, i.e. one of the previously reported pathways for 3,4-DCA. However, the other three isomers are degraded via previously undescribed dichloroaminophenol intermediates. The mechanistic basis for this isomer-specific degradation is discussed.

\section{METHODS}

Chemicals. All DCA isomers, 3,4-dichloroacetanilide and formic acid were obtained from Sigma-Aldrich. Solvents were obtained from Merck. 
Table 1. Known DCA-degrading bacterial strains

\begin{tabular}{|c|c|c|c|}
\hline Bacterial strain & Activity on & Comments on metabolic route & Reference \\
\hline Acidovorax sp. & 3,4-DCA & 3,4-DCA mineralization but no metabolites observed & Dejonghe et al. (2002) \\
\hline Alcaligenes faecalis $\mathrm{H} 1$ & 3,4-DCA & 3,4-DCA mineralization via. 4,5-dichloropyrocatechol & Surovtseva et al. (1993) \\
\hline Comamonas testosteroni WDL7 & 3,4-DCA & $\begin{array}{l}\text { Plasmid-mediated mineralization of 3,4-DCA but no } \\
\text { metabolites observed }\end{array}$ & $\begin{array}{l}\text { Dejonghe et al. (2002); } \\
\text { Surovtseva et al. (1993) }\end{array}$ \\
\hline Delftia acidovorans WDL34 & 3,4-DCA & 3,4-DCA mineralization but no metabolites observed & Dejonghe et al. (2003) \\
\hline Paracoccus denitrificans $3 \mathrm{XA}$ & 3,4-DCA & 3,4-DCA mineralization but no metabolites observed & Surovtseva et al. (1981) \\
\hline $\begin{array}{l}\text { Pseudomonas diminuta } \\
\text { INMI KS-7 }\end{array}$ & 3,4-DCA & $\begin{array}{l}\text { Different dehalogenated products identified during } 3 \text {, } \\
\text { 4-DCA mineralization }\end{array}$ & $\begin{array}{l}\text { Surovtseva et al. }(1985, \\
1986)\end{array}$ \\
\hline Pseudomonas fluorescens $26-\mathrm{K}$ & 3,4-DCA & $\begin{array}{l}\text { 3,4-DCA mineralization via } 2 \text {-amino-4-chlorophenol; } \\
\text { trace amounts of 3,4-dichloroacetanilide and } 3,3^{\prime}, 4 \\
4^{\prime} \text {-tetrachloroazoxybenzene also identified }\end{array}$ & Surovtseva et al. (1981) \\
\hline Pseudomonas putida strain & 3,4-DCA & $\begin{array}{l}\text { Cometabolic mineralization of 3,4-DCA (along with } \\
\text { aniline) via 4,5-dichlorocatechol, 3,4-dichloro- } \\
\text { muconate, 3-chlorobutenolide, 3-chloromaleyl } \\
\text { acetate, and 3-chloro-4-ketoadipate }\end{array}$ & You \& Bartha (1982) \\
\hline Pseudomonas sp. Bk8 & 3,4-DCA & $\begin{array}{l}\text { Diuron mineralization via 3,4-DCA; no further } \\
\text { metabolites observed }\end{array}$ & El-Deeb et al. (2000) \\
\hline Pseudomonas sp. KB35B & 3,4-DCA & $\begin{array}{l}\text { 3,4-DCA mineralization and chlorocatechol-2,3- } \\
\text { dioxygenase activity observed }\end{array}$ & Kim et al. (2007) \\
\hline Rhodococcus sp. strain 2 & 3,4-DCA & $\begin{array}{l}\text { Co-metabolic transformation of 3,4-DCA under } \\
\text { anaerobic conditions; 3,4-dichloroacetanilide, 3,4- } \\
\text { dichloro- } N \text {-(3,4-dichlorophenyl)benzamide and 1,2- } \\
\text { dichlorobenzene identified as intermediates }\end{array}$ & Travkin et al. (2002) \\
\hline Rhodococcus sp. T1-1 & 5 DCA isomers & $\begin{array}{l}\text { Vinclozolin mineralization via 3,5-DCA; 2,3-, 2,4-, } \\
\text { 2,5- and 3,4-DCA also mineralized but no metabolites } \\
\text { observed during growth on any of the DCA isomers }\end{array}$ & Lee et al. (2008) \\
\hline Variovorax sp. SRS16 & 3,4-DCA & $\begin{array}{l}\text { Diuron and linuron mineralization via 3,4-DCA; no } \\
\text { further metabolites observed }\end{array}$ & Sørensen et al. (2008) \\
\hline Variovorax sp. WDL1 & 3,4-DCA & $\begin{array}{l}\text { Linuron mineralization via 3,4-DCA; no further } \\
\text { metabolites observed }\end{array}$ & Dejonghe et al. (2003) \\
\hline
\end{tabular}

Media and growth conditions. Minimal medium (MM) consisted of $1.36 \mathrm{~g} \mathrm{KH}_{2} \mathrm{PO}_{4}, 1.78 \mathrm{~g} \mathrm{Na}_{2} \mathrm{PO}_{4} .2 \mathrm{H}_{2} \mathrm{O}, 0.50 \mathrm{~g} \mathrm{MgSO} 4.7 \mathrm{H}_{2} \mathrm{O}$ and $0.50 \mathrm{~g} \mathrm{NH}_{4} \mathrm{Cl}$ per litre. The $\mathrm{pH}$ was adjusted to 7.2 with $\mathrm{NaOH}$, and $1 \mathrm{ml}$ of trace elements solution $\left[0.10 \mathrm{~g} \mathrm{Al}(\mathrm{OH})_{3}, 0.05 \mathrm{~g} \mathrm{SnCl}_{2} .2 \mathrm{H}_{2} \mathrm{O}\right.$, $0.05 \mathrm{~g}$ KI, $0.05 \mathrm{~g} \mathrm{LiCl}, 0.08 \mathrm{~g} \quad \mathrm{MnSO}_{4}, 0.05 \mathrm{~g} \mathrm{H}_{3} \mathrm{BO}_{3}, 0.10 \mathrm{~g}$ $\mathrm{ZnSO}_{4} .7 \mathrm{H}_{2} \mathrm{O}, 0.01 \mathrm{~g} \mathrm{CoCl}_{2}, 0.01 \mathrm{~g} \mathrm{NiSO}_{4} .6 \mathrm{H}_{2} \mathrm{O}, 0.05 \mathrm{~g} \mathrm{BaCl}_{2}$ and $\left.0.05 \mathrm{~g}\left(\mathrm{NH}_{4}\right)_{6} \mathrm{Mo}_{7} \mathrm{O}_{24} \cdot 4 \mathrm{H}_{2} \mathrm{O}\right]$ per litre was also added. Individual DCA isomers were added to the MM from stock solutions prepared in dichloromethane and used at final concentrations of $0.30 \mathrm{mM}$ (50 p.p.m.). The dichloromethane was evaporated by shaking the medium well before inoculation. Nutrient agar (NA) and nutrient broth $(\mathrm{NB})$ were used as rich media for bacterial growth.

Soil enrichment and isolation of the 3,4-DCA-mineralizing micro-organism. Soil samples were collected from a local agricultural field in Chandigarh, India, with a history of repeated exposure to the herbicide diuron. $\mathrm{MM}(100 \mathrm{ml})$ containing $0.3 \mathrm{mM} \mathrm{3,4-DCA}$ was inoculated with $1 \mathrm{~g}$ of pooled soil samples and incubated at $28{ }^{\circ} \mathrm{C}$ in an Erlenmeyer flask on a rotary shaker at 150 r.p.m., with the addition of a further $0.3 \mathrm{mM}$ 3,4-DCA after 15 days. After a further 15 days this culture $(1 \%, \mathrm{v} / \mathrm{v})$ was transferred to $100 \mathrm{ml}$ fresh medium supplemented with $0.3 \mathrm{mM} \mathrm{3,4-DCA}$ as above and then incubated at $28{ }^{\circ} \mathrm{C}$ for another month, again with the addition of a further $0.3 \mathrm{mM}$ 3,4-DCA at day 15. After five rounds of such enrichment cycles the growth medium was plated onto MM agar plates containing $0.3 \mathrm{mM} 3,4-\mathrm{DCA}$ as sole carbon source and incubated at $28{ }^{\circ} \mathrm{C}$ for $48 \mathrm{~h}$. Individual bacterial colonies were then tested for 3,4-DCA mineralization in MM by HPLC as described below.

Identification of 3,4-DCA-degrading bacteria. The IMT21 strain which was found to be kinetically most efficient at degrading 3,4DCA was identified by the Microbial Type Culture Collection (MTCC), Chandigarh, India, using polyphasic taxonomic methods (Vandamme et al., 1996). The nucleotide sequence of the 16S rRNA gene (1448 bp) was determined by the direct PCR sequencing method using the universal $16 \mathrm{~S}$ primers $8 \mathrm{~F}$ and $1492 \mathrm{R}$ (Baker et al., 2003). The nucleotide sequence was compared with sequences in the nonredundant database using a BLAST search (Zhang et al., 2000).

HPLC and LC-MS analysis. An Agilent series LC system controlled by Agilent TOF software (version A.01.00) (Agilent Technologies) was used for quantitative analysis of DCA isomers and metabolites. The compounds were separated at $25{ }^{\circ} \mathrm{C}$ on an Aqua C18 (5 $\mu$ m particle size, $250 \times 4.60 \mathrm{~mm}$ ) column (Phenomenex) using acetonitrile/water $(50: 50, \mathrm{v} / \mathrm{v}$; both containing $0.1 \%, \mathrm{v} / \mathrm{v}$, formic acid) as mobile phase

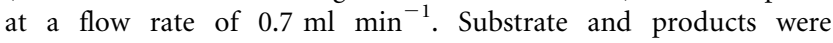
monitored at $250 \mathrm{~nm}$.

Qualitative analysis of DCA isomers was performed using an LC/MS TOF mass spectrometer (Agilent Technologies) with an electrospray ionization (ESI) source. The mass spectrometer was connected to the HPLC stream after the DAD detector. Nitrogen was used at a flow rate of $121 \mathrm{~min}^{-1}$ as drying gas. The capillary temperature was $350{ }^{\circ} \mathrm{C}$ and the spray voltage was $3 \mathrm{kV}$. The scanning was done in positive- 
ion mode and the fragmenter and skimmer were set at $120 \mathrm{~V}$ and $60 \mathrm{~V}$, respectively for scans in the range $50-450 \mathrm{~m} / \mathrm{z}$.

Growth and resting-cell studies. For studies of growth kinetics, $0.5 \mathrm{ml}$ aerobically grown seed culture of strain IMT2 1 in nutrient broth was inoculated in $50 \mathrm{ml}$ minimal medium containing $0.3 \mathrm{mM}$ of one of the five DCA isomers tested and incubated with shaking (200 r.p.m.) at $28{ }^{\circ} \mathrm{C}$. Samples $(0.5 \mathrm{ml})$ were collected from the incubated cultures at different time points, centrifuged at $12000 \mathrm{~g}$ and filtered with $0.22 \mu \mathrm{m}$ filters (Millipore). The filtrate was used for the HPLC and LC-MS analysis.

For resting-cell studies, NB-grown cells of strain IMT21 $(300 \mathrm{ml})$ were harvested in the mid-exponential phase $\left(\mathrm{OD}_{600} \sim 0.5\right)$, washed with $300 \mathrm{ml}$ ice-cold $\mathrm{MM}$ and finally resuspended in $30 \mathrm{ml}$ ice-cold MM. A DCA isomer was added as a filter-sterilized solution at a final concentration of $0.30 \mathrm{mM}$ and $0.5 \mathrm{ml}$ aliquots were removed at different time points, centrifuged and filtered prior to analysis by HPLC and LC-MS. Quantitative analysis was done with HPLC using a standard curve prepared with authentic standards. The experiments were performed in triplicate with appropriate controls.

\section{RESULTS AND DISCUSSION}

Approximately $50 \%$ degradation of $0.3 \mathrm{mM} 3,4$-DCA was observed within 15 days after five rounds of enrichment culture (data not shown). Different dilutions of this enrichment were plated onto MM plates containing 3,4DCA as a sole carbon source, and 12 morphologically distinct bacterial colonies appeared after 30 days of incubation at $30{ }^{\circ} \mathrm{C}$. These were picked and checked individually for 3,4-DCA degradative activity in liquid cultures as described above. The fastest-degrading strain, IMT21, degraded $\sim 60 \%$ of $0.3 \mathrm{mM}$ 3,4-DCA within 20 days.

Strain IMT21 was a Gram-positive, motile, sporulating, catalase- and oxidase-positive, long rod-shaped bacterium which formed tiny creamish-white colonies after overnight incubation on NB plates at $30{ }^{\circ} \mathrm{C}$. The strain hydrolysed aesculin, Tween 20, starch and gelatin, and showed acid production from D-fructose, glycerol, maltose, galactose, Dmannose and D-ribose. Tetradecanoic acid (16:0), 13methylpentadecanoic acid (15:0 iso) and 12-methyltetradecanoic acid (15:0 anteiso) were its major fatty acids. After PCR amplification and sequencing, its 16S rRNA gene (GenBank accession no. GU479395) showed highest sequence similarity with the genus Bacillus, with $100 \%$ identity to several Bacillus megaterium strains (GenBank accession numbers GU191918, GQ406847, EU880506 and EU723818). Based on its physiological characteristics, morphological and biochemical tests and 16S rDNA gene sequence, strain IMT21 was therefore named Bacillus megaterium IMT21.

Strain IMT21 mineralized 2,3-, 2,4-, 2,5-, 3,4- and 3,5DCA as sole sources of carbon and energy in MM (Fig. 1). 2,3-, 2,4- and 2,5-DCA were degraded at comparable rates, and complete degradation was observed within 20 days. However, 30 days were required for complete degradation of 3,4- and 3,5-DCA (data not shown). No metabolites were detected by LC-MS during growth of IMT21 on any of the five tested DCA isomers. The relative degradation rates for the different DCA isomers by this strain are somewhat different from those reported by Lee et al. (2008) for Rhodococcus sp. T1-1 (2,5-DCA $>2,4-\mathrm{DCA}>3,5-$ DCA $>2,3-D C A>3,4-D C A)$, which is the only other bacterium so far reported that can also mineralize these five DCA isomers. Rhodococcus sp. T1-1 was isolated by enrichment culture from a pesticide-contaminated soil sample and was reported to mineralize the fungicidal carbamate vinclozolin (Lee et al., 2008). 3,5-DCA is a toxic metabolite produced in the (bio)degradation of vinclozolin. Interestingly, the isomer degraded most slowly by both (a)

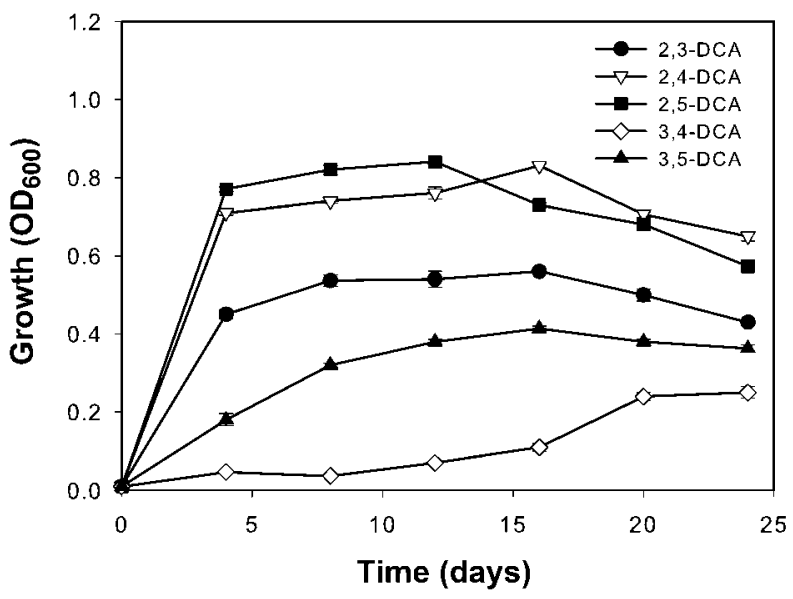

(b)

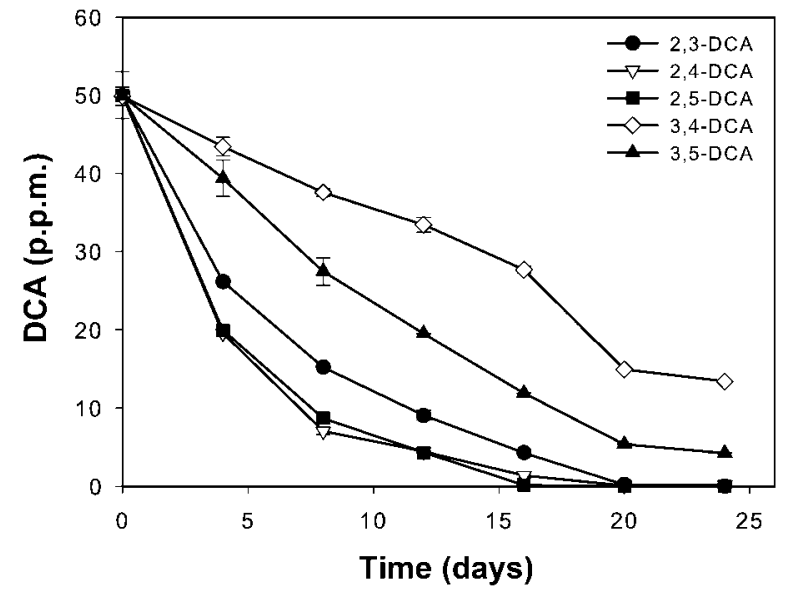

Fig. 1. Growth (a) and degradation kinetics (b) of $B$. megaterium IMT21 on different DCA isomers as sole sources of carbon and energy. 
the strains was 3,4-DCA, which is also the most toxic of the five isomers (NTP Comparative Toxicity Studies, 1998; Padmanabhan et al., 2006; Valentovic et al., 1995). Another similarity with our findings is that Lee et al. (2008) were also unable to detect any metabolites during the growth of strain T1-1 on any of the five DCA isomers tested by HPLC.

Indeed no metabolites have yet been reported nor catabolic pathway proposed for most of the 3,4-DCA-degrading bacterial strains so far characterized (Table 1). However, those few reports where metabolites have been detected implicate three different 3,4-DCA catabolic pathways (Table 1). The first involves direct oxidative deamination of the aromatic nucleus, resulting in dichlorocatecholic intermediates which are assimilated via ring cleavage. This pathway has been exemplified in a Pseudomonas putida strain in which 3,4-DCA is co-metabolically mineralized in the presence of aniline via 4,5-dichlorocatechol, which is assimilated via 3,4-dichloromuconate, 3-chlorobutinolide, 3-chloromaleylacetate and 3-chloro-4-ketoadipate (You \& Bartha, 1982). A second pathway, in this case initiated by reductive deamination, has been described for Rhodococcus sp. strain 2 (Travkin et al., 2002). In this case 1,2dichlorobenzene (1,2-DCB) was identified as a catabolic intermediate under nitrate-reducing anaerobic conditions (Travkin et al., 2002). Although no further intermediate was observed in this strain, degradation of 1,2-DCB or other dichlorobenzene isomers via catecholic intermediates has been described for other bacterial strains (Haigler et al., 1988; Spain \& Nishino, 1987; Spiess et al., 1995; Vandamme et al., 1996). The third pathway is proposed to involve an initial oxidative removal of a chlorine atom from the 3,4-DCA molecule. Evidence for this pathway is the transient appearance of 2-chloro-4-aminophenol during 3,4-DCA mineralization by Pseudomonas fluorescens 26K (Travkin et al., 2003). Enhanced catechol-2,3-dioxygenase activity observed in cultures of strain $26-\mathrm{K}$ and Pseudomonas sp. KB35B when grown in the presence of 3,4-DCA also suggests that this pathway proceeds further via catecholic intermediates (Kim et al., 2007; Travkin et al., 2003).

Resting-cell studies with NB-grown cultures were used to elucidate the catabolic pathways of the different DCA isomers by strain IMT21. Aqueous samples collected at different time points were analysed by LC-MS $(\mathrm{ES}+)$. Culture supernatants incubated with 2,4- and 2,5-DCA each resulted in one transient metabolite peak at $24 \mathrm{~h}$ and $48 \mathrm{~h}$ with the elemental composition of $\mathrm{C}_{6} \mathrm{H}_{5} \mathrm{NCl}_{2} \mathrm{O}+\mathrm{H}^{+}$ $(\mathrm{m} / z$ 177.98), at retention times 8.46 and $5.01 \mathrm{~min}$, respectively. Two metabolite peaks at 4.69 and $7.54 \mathrm{~min}$ with exactly the same elemental composition appeared transiently in the case of 2,3-DCA at $24 \mathrm{~h}$. This empirical elemental composition is interpreted as the monohydroxylated metabolite of the DCA isomers, dichloroaminophenol. The observed mass spectra of the metabolite matched precisely with the in silico-generated mass spectra of the elemental composition above. Dichloroaminophenol would probably result from direct hydroxylation of the aromatic ring without dechlorination or deamination. This metabolite has not been reported previously for DCA degradation, but another phenolic metabolite, 2-amino-4-chlorophenol, has been reported as an intermediate in the degradation of 3,4-DCA by $P$. fluorescens $26-\mathrm{K}$ and it is argued that this is then further (a)

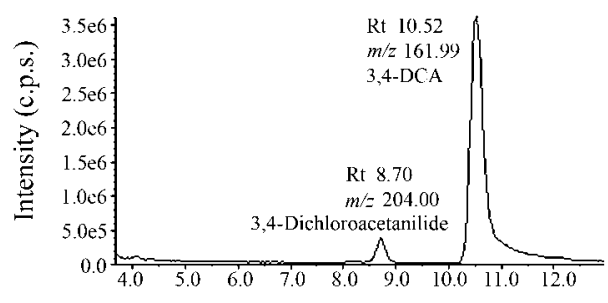

(d)

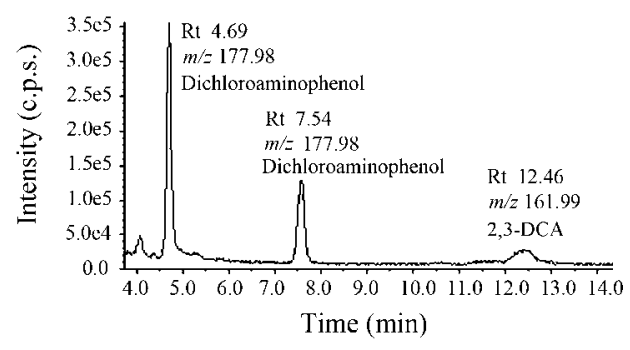

(b)

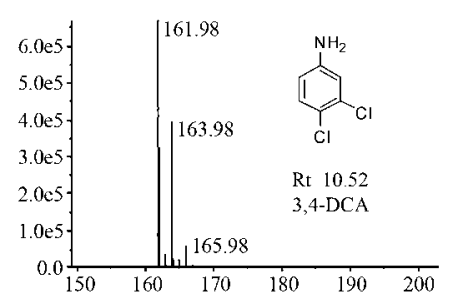

(e)

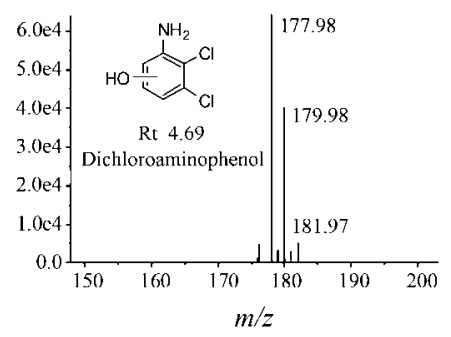

(c)

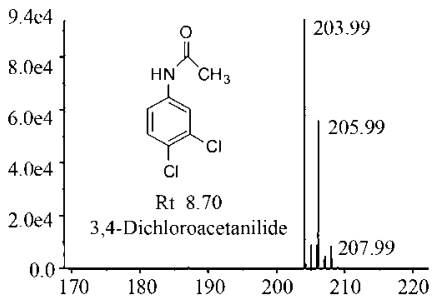

(f)

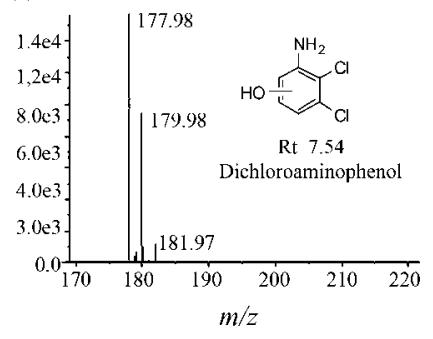

Fig. 2. LC-MS extracted ion chromatograms showing metabolite peaks of (a) 3,4-DCA and (d) 2,3-DCA, and LC-MS TOF spectra of the pseudomolecular ions $\left(\mathrm{m} / z+\mathrm{H}^{+}\right)$of $3,4-\mathrm{DCA}(\mathrm{b})$, the 3,4-dichloroacetanilide (c) from panel (a), and the dichloroaminophenol metabolites (e and f) from panel (d). Rt, retention time. 
degraded via catechol (see above and Kim et al., 2007). Simultaneous monohydroxylation and dechlorination have also been reported previously for highly chlorinated benzenes, such as hexachlorobenzene (HCB). This bacterial degradation of $\mathrm{HCB}$ via a monooxygenation reaction to form pentachlorophenol has been shown in a pentachlorophenol degrader, Sphingobium chlorophenolicum ATCC 39723, after a cytochrome P-450 cam variant was inserted into it (Yan et al., 2006) A similar reaction has recently been shown in the HCB-degrading Nocardioides sp. strain PD653 (Takagi et al., 2009). Interestingly, pentachlorophenol is further degraded via a hydroquinone pathway in both these latter strains, which raises the possibility that dichloroaminophenol produced by the monohydroxylation of 2,3-, 2,4and 2,5-DCA in strain IMT21 may also be further degraded via a hydroquinone pathway.

A single metabolite peak with the elemental composition $\mathrm{C}_{8} \mathrm{H}_{7} \mathrm{Cl}_{2} \mathrm{NO}+\mathrm{H}^{+}(\mathrm{m} / z$ 203.99) transiently appeared in culture supernatant incubated with 3,4 - or 3,5-DCA (retention times 10.52 and $10.49 \mathrm{~min}$, respectively) at $24 \mathrm{~h}$. This empirical formula is interpreted as dichloroacetanilide. The observed mass spectra of the metabolite we have detected match precisely with the in silico-generated mass spectra of its elemental composition. Furthermore, the retention time and mass spectra matched those of an authentic 3,4-dichloroacetanilide standard (data not shown). Representative LC-MS profiles of 2,3- and 3,4-DCA along with pseudomolecular ions $\left(\mathrm{m} / z+\mathrm{H}^{+}\right)$of dichloroaminophenol and 3,4-dichloroacetanilide are shown in Fig. 2.

3,4-Dichloroacetanilide has previously been observed as a minor metabolite in the degradation of 3,4-DCA in Rhodococcus sp. strain 2 under anaerobic conditions, although a complete pathway involving it as a catabolic intermediate was not established (Travkin et al., 2002) Twenty-two different Pseudomonas strains were tested by Vol'nova et al. (1980) for the ability to acetylate 3,4-DCA under co-metabolic conditions, as none of them could mineralize 3,4-DCA as a sole source of carbon and energy. Eleven of the tested strains were found to have the acetylation activity. A recent study involving the model fungus Podospora anserina has also conclusively demonstrated acetylation as a detoxification strategy for various toxic aromatic amines, including 3,4-DCA (Martins et al., 2009). Targeted gene-disruption experiments showed that an arylamine $N$-acetyltransferase enzyme was essential for growth and survival of the fungus in the presence of 3,4-DCA and other toxic aromatic amines. This acetyltransferase, named PaNAT2, was further demonstrated to bioremediate 3,4-DCA in experimentally contaminated soils in a proof-of-concept bioremediation experiment (Martins et al., 2009).

To the best of our knowledge, no predicted catabolic pathway nor any intermediate has previously been reported for the aerobic degradation of 2,3-, 2,4- and 2,5-DCA by a single bacterial isolate, although reductive dehalogenation of 2,4-DCA via 3-chloroaniline and 4-chlorocatechol has been reported for an anaerobic consortium of bacteria (Struijs \& Rogers, 1989).

In conclusion, surprisingly little work has been done on the microbial degradation of DCA isomers despite their notoriety as environmental pollutants. To the best of our knowledge, Bacillus sp. IMT21 and the previously described Rhodococcus sp. T1-1 are the only known bacterial strains that can mineralize the five different DCA isomers in question without a requirement for any other carbon source. No metabolic intermediate or pathway has been proposed for strain T1-1 and, although several metabolites belonging to three catabolic routes have been proposed for 3,4-DCA degradation in various bacteria (see above), no degradation intermediates or catabolic routes have so far been proposed for the other four DCA isomers. Strain IMT21 degrades 2,3-, 2,4- and 2,5-DCA via the respective dichloroaminophenols and it degrades 3,4and 3,5-DCA via acetanilide intermediates.

\section{ACKNOWLEDGEMENTS}

This work was supported in part by Cotton Catchment Communities $\mathrm{CRC}$ and the Indo-Australian Biotechnology Fund. Xie-Feng Yao and Fazlurrahman Khan acknowledge the China Scholarship Council and CSIR-UGC, Government of India, respectively, for providing their research fellowships.

\section{REFERENCES}

Argese, E., Bettiol, C., Agnoli, F., Zambon, A., Mazzola, M. \& Ghirardini, A. V. (2001). Assessment of chloroaniline toxicity by the submitochondrial particle assay. Environ Toxicol Chem 20, 826-832.

Baker, G. C., Smith, J. J. \& Cowan, D. A. (2003). Review and re-analysis of domain-specific 16S primers. J Microbiol Methods 55, 541-555.

Claver, A., Ormad, P., Rodriguez, L. \& Ovelleiro, J. L. (2006). Study of the presence of pesticides in surface waters in the Ebro river basin (Spain). Chemosphere 64, 1437-1443.

Dejonghe, W., Goris, J., Dierickx, A., Dobbeleer, V., Crul, K., Vos, P., Verstraete, W. \& Top, E. M. (2002). Diversity of 3-chloroaniline and 3,4-dichloroaniline degrading bacteria isolated from three different soils and involvement of their plasmids in chloroaniline degradation. FEMS Microbiol Ecol 42, 315-325.

Dejonghe, W., Berteloot, E., Goris, J., Boon, N., Crul, K., Maertens, S., Höfte, M., De Vos, P., Verstraete, W. \& Top, E. M. (2003). Synergistic degradation of linuron by a bacterial consortium and isolation of a single linuron-degrading Variovorax strain. Appl Environ Microbiol 69, 1532-1541.

El-Deeb, B. A., Ali, A. M. \& Ali, K. A. (2000). Some evidences for the involvement of plasmid in diuron herbicide degradation. Acta Microbiol Immunol Hung 47, 63-73.

Giacomazzi, S. \& Cochet, N. (2004). Environmental impact of diuron transformation: a review. Chemosphere 56, 1021-1032.

Götz, R., Bauer, O. H., Friesel, P. \& Roch, K. (1998). Organic trace compounds in the water of the River Elbe near Hamburg, Part I. Chemosphere 36, 2085-2101.

Haigler, B. E., Nishino, S. F. \& Spain, J. C. (1988). Degradation of 1,2dichlorobenzene by a Pseudomonas sp. Appl Environ Microbiol 54, 294-301. 
Kim, Y. M., Park, K., Kim, W. C., Shin, J. H., Kim, J. E., Park, H. D. \& Rhee, I. K. (2007). Cloning and characterization of a catecholdegrading gene cluster from 3,4-dichloroaniline degrading bacterium Pseudomonas sp. KB35B. J Agric Food Chem 55, 4722-4727.

Lee, J. B., Sohn, H. Y., Shin, K. S., Kim, J. S., Jo, M. S., Jeon, C. P., Jang, J. O., Kim, J. E. \& Kwon, G. S. (2008). Microbial biodegradation and toxicity of vinclozolin and its toxic metabolite 3,5-dichloroaniline. J Microbiol Biotechnol 18, 343-349.

Lo, H. H., Brown, P. I. \& Rankin, G. O. (1990). Acute nephrotoxicity induced by isomeric dichloroanilines in Fischer 344 rats. Toxicology 63, 215-231.

Martins, M., Rodrigues-Lima, F., Dairou, J., Lamouri, A., Malagnac, F., Silar, P. \& Dupret, J. M. (2009). An acetyltransferase conferring tolerance to toxic aromatic amine chemicals: molecular and functional studies. J Biol Chem 284, 18726-18733.

NTP Comparative Toxicity Studies (1998). NTP comparative toxicity studies of $o^{-}, m$-, and $p$-chloroanilines (CAS nos. 95-51-2; 108-42-9; and $106-47-8$ ) administered by gavage to $\mathrm{F} 344 / \mathrm{N}$ rats and $\mathrm{B} 6 \mathrm{C} 3 \mathrm{~F} 1$ mice. Toxic Rep Ser 43, 1-F20.

Padmanabhan, J., Parthasarathi, R., Subramanian, V. \& Chattaraj, P. K. (2006). Theoretical study on the complete series of chloroanilines. J Phys Chem A 110, 9900-9907.

Peng, J. F., Liu, J. F., Jiang, G. B., Tai, C. \& Huang, M. J. (2005). Ionic liquid for high temperature headspace liquid-phase microextraction of chlorinated anilines in environmental water samples. J Chromatogr A 1072, 3-6.

Sørensen, S. R., Albers, C. N. \& Aamand, J. (2008). Rapid mineralization of the phenylurea herbicide diuron by Variovorax sp. strain SRS16 in pure culture and within a two-member consortium. Appl Environ Microbiol 74, 2332-2340.

Spain, J. C. \& Nishino, S. F. (1987). Degradation of 1,4-dichlorobenzene by a Pseudomonas sp. Appl Environ Microbiol 53, 1010-1019.

Spiess, E., Sommer, C. \& Gorisch, H. (1995). Degradation of 1,4dichlorobenzene by Xanthobacter flavus 14p1. Appl Environ Microbiol 61, 3884-3888.

Struijs, J. \& Rogers, J. E. (1989). Reductive dehalogenation of dichloroanilines by anaerobic microorganisms in fresh and dichlorophenolacclimated pond sediment. Appl Environ Microbiol 55, 2527-2531.

Surovtseva, E. G., Vasil'eva, G. K., Baskunov, B. P. \& Vol'nova, A. I. (1981). Decomposition of 3,4-dichloroaniline by an Alcaligenes faecalis culture. Mikrobiologiia 50, 740-743.
Surovtseva, E. G., Ivoilov, V. S., Karasevich, Y. N. \& Vaci'ev, G. K. (1985). Chlorinated anilines, a source of carbon, nitrogen, and energy for Pseudomonas diminuta. Mikrobiologiia 54, 948-952.

Surovtseva, E. G., Ivoilov, V. S. \& Karasevich, Y. N. (1986). Metabolism of chlorinated anilines by Pseudomonas diminuta. Mikrobiologiia 55, 591-595.

Surovtseva, E. G., Sukhikh, A. P. \& Ivoilov, V. S. (1993). Isozymes of the pathway for aniline and 4-chloroaniline preparatory metabolism in Alcaligenes sp. Mikrobiologiia 61, 99-106.

Takagi, K., Iwasaki, A., Kamei, I., Satsuma, K., Yoshioka, Y. \& Harada, N. (2009). Aerobic mineralization of hexachlorobenzene by newly isolated pentachloronitrobenzene-degrading Nocardioides sp. strain PD653. Appl Environ Microbiol 75, 4452-4458.

Travkin, V., Baskunov, B. P., Golovlev, E. L., Boersma, M. G., Boeren, S., Vervoort, J., van Berkel, W. J., Rietjens, I. M. \& Golovleva, L. A. (2002). Reductive deamination as a new step in the anaerobic microbial degradation of halogenated anilines. FEMS Microbiol Lett 209, 307-312.

Travkin, V. M., Solyanikova, I. P., Rietjens, I. M., Vervoort, J., van Berkel, W. J. \& Golovleva, L. A. (2003). Degradation of 3,4dichloro- and 3,4-difluoroaniline by Pseudomonas fluorescens 26-K. J Environ Sci Health B 38, 121-132.

Valentovic, M. A., Ball, J. G., Anestis, D. K. \& Rankin, G. O. (1995). Comparison of the in vitro toxicity of dichloroaniline structural isomers. Toxicol In Vitro 9, 75-81.

Vandamme, P., Pot, B., Gillis, M., de Vos, P., Kersters, K. \& Swings, J. (1996). Polyphasic taxonomy, a consensus approach to bacterial systematics. Microbiol Rev 60, 407-438.

Vol'nova, A. I., Surovtseva, E. G. \& Vasil'eva, G. K. (1980). Acetylation of 3,4-dichloroaniline by representatives of the genus Pseudomonas. Mikrobiologiia 49, 167-170.

Yan, D. Z., Liu, H. \& Zhou, N. Y. (2006). Conversion of Sphingobium chlorophenolicum ATCC 39723 to a hexachlorobenzene degrader by metabolic engineering. Appl Environ Microbiol 72, 2283-2286.

You, I. S. \& Bartha, R. (1982). Stimulation of 3,4-dichloroaniline mineralization by aniline. Appl Environ Microbiol 44, 678-681.

Zhang, Z., Schwartz, S., Wagner, L. \& Miller, W. (2000). A greedy algorithm for aligning DNA sequences. J Comput Biol 7, 203-214.

Edited by: D. J. Arp 